Filigrane

Écoutes psychanalytiques

\title{
Hommage à Annie Anzieu, 1924-2019
}

\section{Christine Anzieu-Premmereur}

Volume 28, numéro 2, 2019

URI : https://id.erudit.org/iderudit/1069691ar

DOI : https://doi.org/10.7202/1069691ar

Aller au sommaire du numéro

\section{Éditeur(s)}

Santé mentale et société

\section{ISSN}

1192-1412 (imprimé)

1911-4656 (numérique)

Découvrir la revue

Citer ce document

Anzieu-Premmereur, C. (2019). Hommage à Annie Anzieu, 1924-2019. Filigrane, 28(2), 7-8. https://doi.org/10.7202/1069691ar d'utilisation que vous pouvez consulter en ligne.

https://apropos.erudit.org/fr/usagers/politique-dutilisation/ 


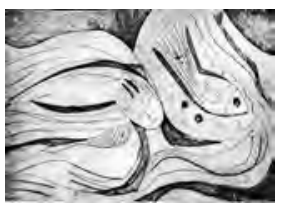

\section{Hommage à Annie Anzieu, 1924-2019}

\section{Christine Anzieu-Premmereur}

\section{nnie Anzieu est décédée le 10 novembre 2019.}

Annie Anzieu est née en France en avril 1924. Diplômée en philosophie et psychologie à Paris à la fin de la Seconde Guerre Mondiale, elle épouse Didier Anzieu en 1947. Tous deux deviennent psychanalystes. Didier a notamment développé ses travaux sur l'auto-analyse de Freud dans les années 50 et sur le Moi-peau durant les années 80. Ils ont vécu à Paris et ont eu deux enfants, Christine et Pascal. Leur fille, Christine AnzieuPremmereur, est également psychanalyste.

En 1958, Annie Anzieu était orthophoniste à l'hôpital de la Salpêtrière à Paris, où le professeur Daniel Widlöcher a fondé avec elle le département de psychothérapie infantile qu'elle a dirigé pendant de nombreuses années. Elle a consacré son temps à enseigner et former de nombreux psychothérapeutes d'enfants.

Elle a été analysée par Georges Favez et est devenue analyste formateur à l'Association psychanalytique de France, fondée en 1964.

En 1984, elle a été nommée présidente de l'Association pour la psychanalyse de l'enfant (APE) qu'elle a fondée avec sa collègue Florence Guignard. En 1994, elles ont toutes deux étendu cette société au niveau européen et fondé la Société européenne pour la psychanalyse de l'enfant et de l'adolescence (SEPEA). Elle a été nommée vice-présidente de la SEPEA la même année.

Grâce à Anne-Marie Sandler, son amie de Londres, l'Association internationale de psychanalyse a créé un Comité sur la psychanalyse des enfants et des adolescents (COCAP), lequel a contribué à la reconnaissance des psychanalystes d'enfants du monde entier. La COCAP a élu Annie Anzieu parmi d'autres collègues européens en tant qu'analyste responsable de la formation en psychanalyse pour enfants et adolescents.

Dans ses travaux sur l'analyse de l'enfant, elle a mis l'accent sur le rôle des relations corporelles et des enveloppes psychiques entre mère et enfant, ainsi que sur le besoin de pouvoir nommer les affects. 
De plus, elle a publié des articles sur la sexualité féminine. Dans son livre La femme sans qualité, elle propose l'idée que la vie psychique d'une femme est sous l'influence de ses représentations de l'intérieur de son corps et de sa réceptivité.

Elle a laissé une empreinte importante dans le monde psychanalytique pour le traitement des enfants, des adolescents et des femmes.

23 novembre 2019 